\title{
Proceeding
}

Supplementary Issue: Autumn Conferences of Sports Science. Costa Blanca Sports Science Events, 18-19 December 2020. Alicante, Spain.

\section{Patient-oriented approach in public health as a factor in the formation of a model of healthy behaviour (formation of sports lifestyle, introduction of individual physical activity)}

\author{
ALEXEY VICTOROVICH SMYSHLYAEV1 1 , ROMAN EVGENYEVICH PETROV², E. LAXMI LYDIA3, HILARY \\ IZUCHUKWU OKAGBUE ${ }^{4}$, MARIYA VLADIMIROVNA MIKHAILOVA ${ }^{5}$, RAFINA RAFKATOVNA ZAKIEVA ${ }^{6}$ \\ ${ }^{1}$ Federal Research Institute for Health Organization and Informatics, Ministry of Health of the Russian Federation, \\ Russian Federation \\ ${ }^{2}$ Kazan Federal University, Elabuga, Russian Federation \\ ${ }^{3}$ Vignan's Institute of Information Technology(A), Visakhapatnam, India \\ ${ }^{4}$ Covenant University, Ota, Nigeria \\ ${ }^{5}$ Sechenov First Moscow State Medical University, Moscow, Russian Federation \\ ${ }^{6}$ Kazan State Power Engineering University, Kazan, Russian Federation
}

\begin{abstract}
Currently, the introduction of the patient-oriented approach in healthcare is relevant in the framework of improving the quality and accessibility of medical care. The aim of the research was to study the conditions and principles of the formation of a patientoriented model of a medical organization. The study used research materials in the field of patient-oriented treatment in healthcare. The main research method was content analysis. The patient-centred approach is based on eight principles: respect for consumer values; integrity of the medical diagnostic process; patient awareness; creation of comfortable conditions; providing emotional support; ensuring the continuity of the treatment process; ensuring access to medical care. The introduction of the patient-oriented approach may be hindered by a number of factors: an inflexible system of remuneration and linking the number of patients served to the level of remuneration. In addition, the key basic principle of the patient-oriented approach is to increase patient compliance and patient loyalty. Thus, when forming patient-oriented management in a medical organization, it is necessary to be guided in decision-making primarily by the interests of the patient. The introduction of the patient-oriented approach leads to increased commitment and loyalty of future patients. The development of a patient-oriented approach is also an important factor in strengthening public health (the formation of a sports lifestyle, the introduction of individual physical activity).
\end{abstract}

Keywords: Patient-oriented approach; Public health; Physical activity.

Cite this article as:

Smyshlyaev, A.V., Petrov, R.E., Lydia, E.L., Okagbue, H.I., Mikhailova, M.V., \& Zakieva, R.R. (2021). Patient-oriented approach in public health as a factor in the formation of a model of healthy behaviour (formation of sports lifestyle, introduction of individual physical activity). Journal of Human Sport and Exercise, 16(2proc), S387-S394. doi:https://doi.org/10.14198/ihse.2021.16.Proc2.23

Corresponding author. Federal Research Institute for Health Organization and Informatics, Ministry of Health of the Russian Federation, Dobrolubova str., 11. 127254, Moscow, Russian Federation.

E-mail: $\underline{b . h o s s e i n i a n . a @ g m a i l . c o m ~}$

Abstract submitted to: Autumn Conferences of Sports Science. Costa Blanca Sports Science Events, 18-19 December 2020. Alicante, Spain.

JOURNAL OF HUMAN SPORT \& EXERCISE ISSN 1988-5202

(c) Faculty of Education. University of Alicante

doi:10.14198/jhse.2021.16.Proc2.23 


\section{INTRODUCTION}

\section{Problem statement}

Currently, according to the World Health Organization (WHO), the national health systems of the participating countries are facing the fight against non-communicable diseases (NCDs). According to the WHO Global Targets NCD program, priority goals are currently to reduce the effects of risk factors such as alcohol abuse, smoking, low physical activity, unbalanced diet, high blood pressure, high blood glucose and cholesterol, and high body weight. In addition, it is necessary to increase the coverage of the population with primary health care (PHC) (Okriashvili et al., 2019; Laskov et al., 2020).

Based on this, we can talk about the need to improve the quality of medical services (mainly by reducing the influence of risk factors for NCDs, early diagnosis and treatment of diseases at the initial stages), as well as increasing the availability of primary care through increasing the coverage of the population with preventive measures. To achieve these goals, it is necessary to introduce a selective approach to the management of medical organizations. The transformation of the concept of a state-centred approach into a socially centred approach to government administration entails changes in the healthcare sector as well. The administrativecommand (bureaucratic) health care management system, which has been evolutionarily obsolete, should be replaced by a patient-oriented (flexible) one based primarily on the patient-centred approach to providing medical care to the population (Global Action Plan for the Prevention and Control of Non-Communicable Diseases 2013-2020).

\section{Research questions}

According to experts of the Food and Drug Administration (USA), it is necessary to formulate, first of all, a personalized approach that will take into account all potential expectations and needs of the patient. Experts from the European Society of Cardiology claim that despite the progressive development of the evidencebased approach in the modern Western European healthcare system, it is worth noting its limitations in the current realities. The development of the patient-personalized approach, as one of the components of the patient-oriented approach, will significantly improve the quality of medical services (the quality of treatment and diagnostic measures, preventive measures, and rehabilitation) (Paving Way for Personalized Medicine. USA: Food and Drug Administration, 2013).

\section{Purpose of the study}

The purpose of the research was to study the conditions and principles of the formation of a patient-oriented model of a medical organization.

\section{METHODOLOGY}

The study used research materials in the field of patient-oriented treatment in healthcare in developing and developed countries. The main research method was a content analysis of scientific and practical sources of literature.

\section{RESULTS AND DISCUSSION}

The concept of Patient-Centred Care appeared in the early 90s, when the Picker Institute \& Harvard Medical School conducted a study and designated the patient-oriented approach as an innovative approach to providing medical care to the population, in which the decision-making system is based on the personified characteristics of the patient, provided by scientifically proven methods. Personified traits include both genetic 
features, individual reactions, a hereditary predisposition, and cultural, social, and psychological factors. In addition, it is necessary to build full-fledged partnerships of the doctor-patient model with the inclusion and full participation of the patient's family in decision-making (Kirchhof et al., 2014). Researchers have also identified eight basic principles of the patient-oriented approach (Table 1).

Table 1. Principles of the patient-oriented approach according to Picker Institute \& Harvard Medical School (1993).

№ Description of the principles of the patient-oriented approach

1. Respect for consumer values, needs and preferences. This means that in the medical diagnostic process of decision-making, it is necessary first of all to take into account the opinion of the patient. The integrity, consistency and continuity of the diagnostic process. It should be understood that

2. patients in this aspect are a vulnerable link. A disease that reduces the quality of life of the patient, paints the psycho-emotional background of mood in negative.

Awareness of the patient about all the details of the treatment and diagnostic process, about the

3. progress of medical and social rehabilitation, etc. Also informing about the forecasts of cure (recovery, remission). This principle is quite broad and covers many aspects.

Creating comfortable conditions for the patient's stay in the process of providing him with medical

4. care at all stages: in an outpatient facility, in a hospital, in rehabilitation groups, etc. Comfortable conditions are also stipulated by convenient formats for providing medical care: a heated room, painless procedures adherence to ethics and deontology.

Providing emotional support for the patient. In implementing this principle, a health care provider

5. should take into account factors such as the patient's concern about his condition, as well as the outcome of the disease.

Creating conditions for the patient to communicate with his immediate environment. Attention should

6. be paid to the level of subjective comfort of the patient, if possible, to providing comprehensive support, not to limit it in communication with relatives, colleagues, friends.

Ensuring the continuity of the treatment process, as well as meeting expectations in terms of its

7. modification over time. To ensure this principle, first of all, it is necessary to convey detailed information about drugs, restrictions, diets in an accessible form.

Adequate access to care for a potential patient. This is physical access to a medical organization,

8. the availability of public transport, the possibility of an unhindered appointment with a doctor, the choice of a doctor, and treatment methods.

\section{Implementing the patient-oriented approach}

One of the first steps in introducing the patient-oriented approach in providing medical care to the population is the need to know the opinion of patients about the quality and accessibility of their medical services (Patel \& Chatterji, 2015). The easiest way is to interview patients "at the exit". First of all, it is necessary to change the interaction model in the structure of interaction with the patient as the final and key consumer of the medical service (Constand et al., 2014; Chiauzzi et al., 2015). It is necessary to ask the question "what would you like to improve in the work of the medical organization", and not "what happened when you visited the medical organization". It should be understood that monitoring the mood and expectations of patients does not lie on the shoulders of medical workers (medical and / or paramedical personnel), but on providing personnel in this area. Medical staff provides the mainstream of organization's values and patient orientation in their relation lies in the field of ethics and deontology of medical activity, the degree of empathy, etc. (Schroeder et al., 2015).

We can talk about a three-level system (structure) of patient-oriented healthcare. At the micro level, the key 
is the doctor-patient relationship, at the middle level it is the medical organization-patient, and at the macro level it is the national patient-health system. Moreover, in a balanced health care system, the basis for this structure is the doctor-patient model. It is the "mother platform" (the basic indivisible element) for the formation of the "medical organization-patient" model. In turn, the "medical organization-patient" model is the basic element for the macro-level model (Granger et al., 2013). In an unbalanced healthcare system, one of the models may prevail amid the degradation of other models. So, for example, with hypertrophy of the doctorpatient model, which prevails in crisis situations (destruction of the national health care system), a private decentralized sector of medical organizations is formed. With the increasing role of the state and centralization of the healthcare system, bureaucratization, and formalization of the diagnostic process, the "doctor-patient" model is degrading. At the same time, an increase in the state's share in the formation of the national health care system, in the absence of effective management tools (a process-oriented approach to managing a medical organization, the introduction of lean technologies in the workplace) and control (independent trade unions, associations, etc.) leads to monopolization of the market for medical servants and the destruction of competitive relationships (Zaripova et al., 2019; Dunets et al., 2020; Bukharina et al., 2014; Kuzmin et al., 2018). The lack of competition in the medical services market is detrimental both to health workers and, of course, to patients. For medical personnel in this situation, the key criterion for professional validity is not the level and breadth of competencies, but loyalty to the employer. For patients, this is, first of all, a decline in the quality of medical services (Rasool, 2015).

Several factors may impede the introduction of the patient-oriented approach to the provision of medical services. First of all, it is a system of professional organization of labour for medical workers. Here one of the key factors is the inflexible system of remuneration. Currently, despite the introduction of effective criteria for assessing employees' labour, the approved system essentially does not take into account the quality of medical services provided (with the exception of formal criteria). Linking the number of patients served to assessing the quality of the services provided and the level of remuneration is not effective in the long term (Thibaut, 2016). Such an approach can led to a formal assessment of the work of medical staff without correlation with the health indicators of the served population. Often, the doctor may seek (if it is a correlation between the level of remuneration and the number of patients) to increase the patient base. This reduces the time spent on each patient individually. Such an approach will inevitably lead to a decline in the quality of medical services, professional burnout, and degradation of the doctor-patient model (Thomas, 2017).

One example of linking the doctor's pay level to the number of patients can be the data of a sociological survey of medical staff conducted by Ernst \& Young Russia in 20 thousand medical organizations in the public and private sectors in 2015 . Thus, more than $45 \%$ of organizations reported that the level of remuneration of employees depends directly on compliance with the plan for the number of patients. A progressive salary scale has been introduced in these organizations depending on the amount of the organization's revenue. At the same time, $55 \%$ of respondents said that their goal is effective treatment of patients and consider linking the size of the salary to the organization's profits detrimental. According to A.Z. Stolpner, linking a doctor's salary to revenue can affect medically ungrounded appointments (diagnostic and treatment procedures, etc.). In his opinion, the practice of co-payment for additional appointments to a doctor is widespread at present in the capital's medical organizations. He insists that the emphasis on the quality of treatment makes the patient return to this clinic and bring his relatives and friends there, thereby increasing the level of trust in the medical organization. It is worth noting that in this approach, the main goal is to increase the level of trust in the brand (brand loyalty) (Zhang \& Hong, 2015).

According to James Alan Robinson, a professor at the University of Chicago, one of the leading experts in the field of health policy and management, all the three existing pay models in the healthcare system 
(payment for individual services, per capita financing, and fixed wage rates) are not perfect (Mellis, 2015; Mathur \& Sutton, 2017; Zhai).

\section{Compliance and patient loyalty}

A key underlying principle of the patient-centred approach is to increase patient compliance and patient loyalty. In this aspect, it is worth distinguishing between these two concepts, although from a linguistic point of view they are certainly synonymous. Separation of these concepts in the formation of the patient-oriented approach is necessary due to the different functional significance (load) of these definitions. The adherence to following the prescribed treatment (adherence to therapy), as well as fulfilling the requirements of the doctor to comply with the medical and protective regime, reflects personal attitude to the doctor-patient system. But this factor is determined by the level of patient confidence in the competence of the doctor, his level of professional training (qualification). According to I.E. Leppik, the category of "commitment" includes several components: the behavioural component (of the patient), its focus on results, as well as the degree of possibility (conditions) of fulfilling assignments. In practice, the level of "adherence" is usually measured by the correctness or incorrectness of the fulfilment of medical prescriptions (following the prescribed doses, observing the time interval, etc.). If the patient takes the drug at a dose of $80-120 \%$ of the prescription, then the level of "commitment" can be regarded as high. In addition to direct assessments of "commitment" there are indirect methods for determining the level of a given indicator. These include the number of tablets used/remaining, questionnaires, checking patient records (diaries), etc (Bardes, 2012).

As for the "loyalty" of the patient, it is more appropriate to consider it in the model of "medical organizationpatient." This indicator reflects both the degree of patient confidence in a particular medical organization (legal entity, institution) and the medical care system as a whole. For example, trust in a private or public health care system or in a "paid" or "free" medicine system. So, according to the BusinesStat Agency, in 2019, more than $27.0 \%$ of residents of Moscow and the Moscow region applied for the services of private medical organizations. A high rate (\%) of referral to commercial clinics against the background of a developed network of state healthcare institutions indicates primarily the degree of trust of respondents. The key reasons were in $35.2 \%$ of cases - the high professional component of doctors according to respondents, in $34.5 \%$ the high effectiveness of the prescribed regimens and procedures. At the same time, $56.4 \%$ of respondents went to see a specific doctor (factor of adherence to the doctor-patient model). The factor of adherence in the "medical organization-patient" model, according to $21.4 \%$ of respondents, was influenced by a good level of organization of medical care (efficiency, completeness of coverage, etc.). In addition to medical organizations, the insurance company may also be included in the circle of subjects of the motivational model "medical organization-patient" (Epstein, 2014). But this aspect matters exclusively in the private sector. As for the public health sector, according to the survey, trust in a doctor (42.4\%) is significantly lower than trust in a medical organization (76.9\%) as a whole (or in the public health system). This is mainly due to the fact that, along with the recognition of low qualification of doctors in the public sector, respondents are aware of the "universal" coverage of state guarantees in the compulsory medical insurance system and the ability to "get" expensive treatment and examination methods if indicated. Clouding this picture, according to $79.9 \%$ of respondents, is the high level of "bureaucratization" of the state system of medical care. At the same time, in the private sector, trust in a doctor is much higher than in a commercial organization as a whole. This is due to the fact that the majority of respondents $(65.5 \%)$ believe that the leadership of such organizations sets the goal of making profits an order of magnitude higher than providing quality medical care (Avisar et al., 2017). 


\section{SUMMARY}

Difficulties in implementing the patient-oriented approach at the system level primarily include integration and access. The implementation of case management practices helps to improve the quality of medical services. A multi-disciplinary patient-centric approach has ensured the rapid and effective integration of innovative treatment regimens. To function efficiently, the capabilities of the system must meet the needs of patients. The problem of inequality of access to medical care remains not fully understood and resolved for most national health systems. The global spread of the Internet and various online communication options has provided clinicians with a unique way to establish communication with patients.

The language barrier is another significant problem that can considerably limit communication between the doctor and the patient. It was also noted that patients who spoke the same language with the doctor were more likely to be properly examined (Taber et al., 2015).

\section{Patient-oriented approach in the practice of health promotion of the population (development of sports, individual physical activity)}

In accordance with the priorities of the strategy of social and economic development of Russia, one of the urgent tasks of our state is the preservation and strengthening of the health of young people, in particular students. The health of citizens is of public interest also due to concern about the health status of specialists graduating from higher education, an increase in morbidity in the process of their professional training, the subsequent decrease in the efficiency of personnel in various sectors of the economy. According to the estimates of authoritative experts, among the main factors of health, the most important is a person's lifestyle. The main components of a healthy lifestyle are: compliance with the regime work and rest, nutrition and sleep, hygienic requirements, organization of an individual optimal mode of physical activity, refusal bad habits, culture of interpersonal communication, culture of sexual behaviour, personality-developing leisure socially approved orientation (Jayadevappa \& Chhatre, 2011).

\section{CONCLUSION}

When forming a patient-oriented management in a medical organization, it is necessary to be guided in decision-making primarily by the interests of the patient (client). The main goal is to increase the patient's confidence in the doctor and in the medical organization as a whole. Interaction in this system is carried out on mutually beneficial conditions and partnerships, which should be reflected in the planning and providing medical services to the population. To assess the activities of a medical organization and the health care system as a whole, it is necessary to take into account the opinion of citizens about the quality control system for medical services and the effectiveness/efficiency of management (McCabe, 2017). The founder of a medical organization should regularly initiate an independent survey of attached patients, which should become the basis for planning the scope and type of medical services. The introduction of the patient-oriented approach with proper implementation leads, first of all, to an increase in the population's appeal, adherence to treatment, which in turn will affect the indicators of the detected diseases, the duration of remissions, the reduction in the incidence rate, as well as the wider coverage of the population with preventive measures (https://www.diary.ru). The development of a patient-oriented approach is also an important factor in strengthening public health, the formation of a sports lifestyle, the introduction of individual physical activity. 


\section{REFERENCES}

Avisar, N. (2017). Multi-disciplinary patient-centered model for the expedited provision of costly therapies in community settings: The case of new medication for hepatitis C. Isr. J. Health Policy Res, 6(1), 155-159. https://doi.org/10.1186/s13584-017-0172-1

Bardes, C.L. (2012). Defining "Patient-Centered Medicine". N. Engl. J. Med, 366(9), 782-783. https://doi.org/10.1056/NEJMp1200070

Bukharina, I. L., Zhuravleva, A. N., Dvoeglazova, A. A., Kamasheva, A. A., Muhametnagimovna, S. A., \& Kuzmin, P. A. (2014). Physiological and biochemical characteristic features of small-leaved lime(tilia cordata mill.) in urban environment. Advances in Environmental Biology, 8(13), 79-83.

Chiauzzi, E., Rodarte, C., \& Das Mahapatra, P. (2015). Patient-centred activity monitoring in the self management of chronic health conditions. BMC Medicine, 13(1). https://doi.org/10.1186/s12916$\underline{015-0319-2}$

Constand, M.K., MacDermid, J.C., Dal Bello-Haas, V., (2014). Scoping review of patient-centred care approaches in healthcare. BMC Health Serv Res, 14, 271. https://doi.org/10.1186/1472-6963-14-271

Dunets, A.N., Yankovskaya, V.V., Plisova, A.B., et al. (2020). Health tourism in low mountains: A case study. Entrepreneurship and Sustainability Issues, 7(3), 2213-2227. https://doi.org/10.9770/jesi.2020.7.3(50)

Epstein, N. (2014). Multidisciplinary in-hospital teams improve patient outcomes: A review. Surg. Neurol. Int, 5(8), 295. https://doi.org/10.4103/2152-7806.139612

Granger, B.B., McBroom, K, Bosworth, H.B., et al. (2013). The meanings associated with medicines in heart failure patients. European Journal of Cardiovascular Nursing, 12(3), 276-283. https://doi.org/10.1177/1474515112447734

Jayadevappa, R., \& Chhatre, S. (2011). Patient centered care - A conceptual model and review of the state of the art. Open Health Serv. Policy J, 4, 15-25. https://doi.org/10.2174/1874924001104010015

Kirchhof, P., Sipido, K.R., Cowie, M.R., et al. (2014). The continuum of personalized cardiovascular medicine: a position paper of the European Society of Cardiology. Eur Heart J, 35(46), 3250-3257. https://doi.org/10.1093/eurheartj/ehu312

Kuzmin, P. A., Bukharina, I. L., \& Kuzmina, A. M. (2018). The reaction of woody plants to growing conditions in the man-made environment. International Journal of Civil Engineering and Technology, 9(11), 878-887.

Laskov, R. P., Ein-Tal, I., \& Cojocaru, L. (2020). How does it feel? Factors predicting emotions and perceptions towards sexual harassment. International journal of criminology and sociology, 9, 37-51.

Mathur, S., \& Sutton, J. (2017). Personalized medicine could transform healthcare (Review). Biomedical Reports, 7(1), 3-5. https://doi.org/10.3892/br.2017.922

McCabe, R. (2017). Involvement in decision making: the devil is in the detail. World Psychiatry, 16(2), 155-156. https://doi.org/10.1002/wps.20414

Mellis, C. (2015). Evidence-based medicine: What has happened in the past 50 years? J. Paediatr. Child Health, 51(1), 65-68. https://doi.org/10.1111/jpc.12800

Okriashvili, T.G., Pavlyuk, B.V., Smyshlyaev, A.V., et al. (2019). Teaching the Public Administration in Health Care in The Russian Federation. International Journal of Higher Education, 8(7), 29-33. https://doi.org/10.5430/ijhe.v8n7p29

Patel, V., \& Chatterji, S. (2015). Integrating mental health in care for non-communicable diseases: An imperative for person-centred care. Health Affairs, 34(9), 1498-1505. https://doi.org/10.1377/hlthaff.2015.0791

Paving Way for Personalized Medicine. USA: Food and Drug Administration, 2013. 
Rasool, M. (2015). The role of epigenetics in personalized medicine: challenges and opportunities. BMC Med. Genomics, 8(1), 5-7. https://doi.org/10.1186/1755-8794-8-S1-S5

Schroeder, M.C., Robinson, J.G., Chapman, C.G., et al. (2015). Use of statins by Medicare beneficiaries post myocardial infarction: Poor physician quality or patient-centred care? Inquiry (United States), 52(1), 1-5. https://doi.org/10.1177/0046958015571131

Taber, J.M., \& Leyva, B., \& Persoskie, A. (2015). Why do People Avoid Medical Care? A Qualitative Study Using National Data. J. Gen. Intern. Med, 30(3), 290-297. https://doi.org/10.1007/s11606-0143089-1

Thibaut, F. (2016). From basic research to personalized medicine. Dialogues Clin. Neurosci, 18(3), 231238. https://doi.org/10.31887/DCNS.2016.18.3/fthibaut

Thomas, D.C. (2017). What does «precision Medicine» Have to Say about Prevention. Epidemiology, 28(4), 479-483. https://doi.org/10.1097/EDE.0000000000000667

Zaripova, R. S., Ahmetova, M. H., \& Kuzmin, P. A. (2019). Ecological and biological features of quickbeam (sorbus aucuparia L.) in the context of an urbanized environment. Journal of Advanced Research in Dynamical and Control Systems, 11(5 Special Issue), 1731-1734.

Zhai, L. Sick money: how increases in the salaries of doctors harm medicine. Notes from Liao Zhai's office. Retrieved from: https://www.diary.ru/ LiaoZhai/p206717484.htm?oam=

Zhang, L., \& Hong, H. (2015). Genomic Discoveries and Personalized Medicine in Neurological Diseases. Pharmaceutics, 7(4), 542-553. https://doi.org/10.3390/pharmaceutics7040542

\section{() $\odot \Theta \Theta$}

This work is licensed under a Attribution-NonCommercial-NoDerivatives 4.0 International (CC BY-NC-ND 4.0). 